\title{
GALC mutations in Chinese patients with late-onset Krabbe disease: a case report
}

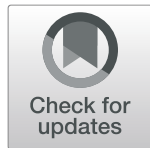

\author{
Shunzhi Zhuang, Lingen Kong, Caiming Li', Likun Chen and Tingting Zhang
}

\begin{abstract}
Background: Krabbe disease (also known as globoid cell leukodystrophy) cause by a deficiency of the enzyme $\beta$-galactocerebrosidase (galactosylceramidase, GALC). The deficiency of GALC leads to accumulation of galactosylceramide and psychosine, the latter GALC substrate having a potential role in triggering demyelination. Typically, the disease has an infantile onset, with rapid deterioration in the first few months, leading to death before the age of 2 years. The late onset forms (late-infantile, juvenile, and adult forms) are rare with variable clinical outcomes, presenting spastic paraplegia as the main symptom.
\end{abstract}

Case presentation: We recruited a family with two affected individuals. The proband (Patient 1), a 25-yearold male, was presented with slow progressive symptoms, including spastic gait disturbance and vision loss since the 5th year of life. His elder sister (Patient 2), became wheelchair-bound and demented at the age of 22 years. Brain magnetic resonance imaging (MRI) showed increased signal intensity in the white matter along with the involvement of the bilateral corticospinal tracts. GALC deficiency was confirmed by biochemical analysis. DNA sequencing revealed two mutations (c.865G > C: p. G289R and c.136G > T: p. D46Y) in GALC. The clinical characteristics, brain MRI, biochemical and molecular findings led to the diagnosis of Krabbe disease.

Conclusion: Clinical and neuroimaged signs, positive enzymatic analysis and molecular data converged to definite diagnosis in this neurodegenerative disease.

Keywords: Krabbe disease, Late-onset, Galactocerebrosidase, GALC gene, Brain MRI

\section{Background}

Krabbe disease (MIM 245200) is a rare inherited metabolic, neurodegenerative disease, due to the deficiency of the enzyme GALC. It is a lysosomal hydrolase, and its deficiency leads to accumulation of galactosylceramide and psychosine. The latter of these GALC substrates is cytotoxic at enhanced concentrations which seem to explain rapid degeneration of myelin-generating cells in Krabbe disease. This severe lysosomal storage disorder starts in the classical earlyinfantile form with a rapid downhill course around the first 6 months of life [1]. Compared to this acute disease form, the late-onset forms have a slower clinical progression [2]. Depending on the time of disease onset, the late-onset forms of Krabbe disease are categorized into [3]: late-infantile (6 months to 3 years),

* Correspondence: caiminglee@21cn.com

Department of Neurology, the First People's Hospital of Huizhou city, 20\# Sanxin south Road, Huizhou 516003, Guangdong Province, China juvenile (3-8 years), and adult [4]. Cerebral MRI, especially on $\mathrm{T} 2 \mathrm{~W}$ scans document the demyelination of the bilateral pyramidal tracts and parieto-occipital white matter [5, 6]. The GALC gene, spanning $60 \mathrm{~kb}$ of genomic DNA on chromosome 14q31, encodes the enzyme $\beta$-galactocerebrosidase, which is critical for glycosphingolipid catabolism [7]. According to the Human Gene Mutation Database (HGMD), more than 130 mutations have been catalogued. At least 128 of them were viewed as being pathogenic of Krabbe disease [8].

Here we report the GALC mutations, a known and a novel one, in Chinese siblings with late-onset Krabbe disease.

\section{Case presentation \\ Patient 1}

A 25-year-old male, from China, born to unrelated parents was presented to the First People's Hospital 
Table 1 Timeline of patient 1

\begin{tabular}{ll}
\hline 1997 & mild gait difficulties, unstable ambulation \\
2000 & vision loss \\
2017 & progressive spastic gait disturbance and vision loss
\end{tabular}

of Huizhou city, China. The clinical manifestations were spastic gait disturbance and vision loss (Table 1) . He was suffering from mild gait difficulties by the age of 5 years; the ambulation was unstable, and he could fall easily. The vision loss was reported at the age of 8 years, while the cognitive development was normal. He was born at full term by uncomplicated delivery. The neurological examination of the patient revealed ocular motility disorders, horizontal nystagmus, absence of the left pupillary light reflex, pes cavus, spastic paraparesis on lower limbs, exaggerated bilateral patellar tendon reflexes, ankle clonus, and positive Babinski sign, while no detectable defect was found in the finger-to-nose test, sensory function. The laboratory biochemical studies of full blood count, liver function, plasma electrolytes, thyroid function, vitamin B-12 and folate, sex hormone, autoantibody profile and syphilis serology exhibited typical levels. Cerebrospinal fluid tests revealed increased protein $(1186 \mathrm{mg} / \mathrm{L})$; the normal value was $140-450$ $\mathrm{mg} / \mathrm{L}$. The GALC enzymatic activity [9] detected by Bio-Tek FLx 800 fluorescent analyzer in leukocytes was decreased $(3.9 \mathrm{nmol} / \mathrm{mg} / 17 \mathrm{~h})$; the normal value was $18-75 \mathrm{nmol} / \mathrm{mg} / 17 \mathrm{~h}$ protein.

The described findings gave reason to perform molecular analysis of the GALC gene. The direct sequencing of the GALC gene (Reference mRNA sequence: NM_000153) in this patient identified a novel missense mutation (c.865G > C: p. G289R) in exon 8 along with a known missense mutation [10] (c.136G > T: p. D46Y) in exon 1 (Figs. 1 and 2). The former mutation was heterozygous in the mother, while the latter was heterozygous in the father.

Brain MRI revealed a high-intensity signal in the left central gyrus cortex by fluid-attenuated inversion recovery (FLAIR) as well as T2-weighted images, while a decreased signal in the T1-weighted images and high-intensity lesions in the bilateral corticospinal tracts were detected (Fig. 3). Cervical spine and thoracic spine MRI showed mild atrophy of the spinal cord (Fig. 4). Moreover, electromyography indicated peripheral nerve demyelination, and both visual evoked potentials (VEP) and brainstem auditory evoked potential (BAEP) were normal.

\section{Patient 2}

In the family history, his elder sister's development was normal until the age of 4 years when spastic gait disturbance and dysarthria were noticed. She suffered from mental and motor regression, and hence, faced difficulties in schooling. She became wheelchairbound and demented at the age of 22 years. She could not understand what was said to her but responded with a smirk. Other family members, including her parents and elder brother, were unaffected at the time of this analysis (Fig. 5). The GALC enzymatic activity revealed $4.4 \mathrm{nmol} / \mathrm{mg} / 17 \mathrm{~h}$. The GALC genotype was also studied in Patient 2. She carried two heterozygous GALC mutations (p.G289R and p.D46Y), the same as the Patient 1 (Fig. 2).

The mutations were analyzed to assess their pathogenicity. The SIFT scores of the mutations were 0.003 (p.G289R) and 0.013 (p.D46Y), respectively, and the Polyphen2 scores were 0.905 (p.G289R) and 1 (p.D46Y), respectively.

Thus, Krabbe disease was diagnosed in both patients. Since effective therapy is limited, Patient 1 was treated

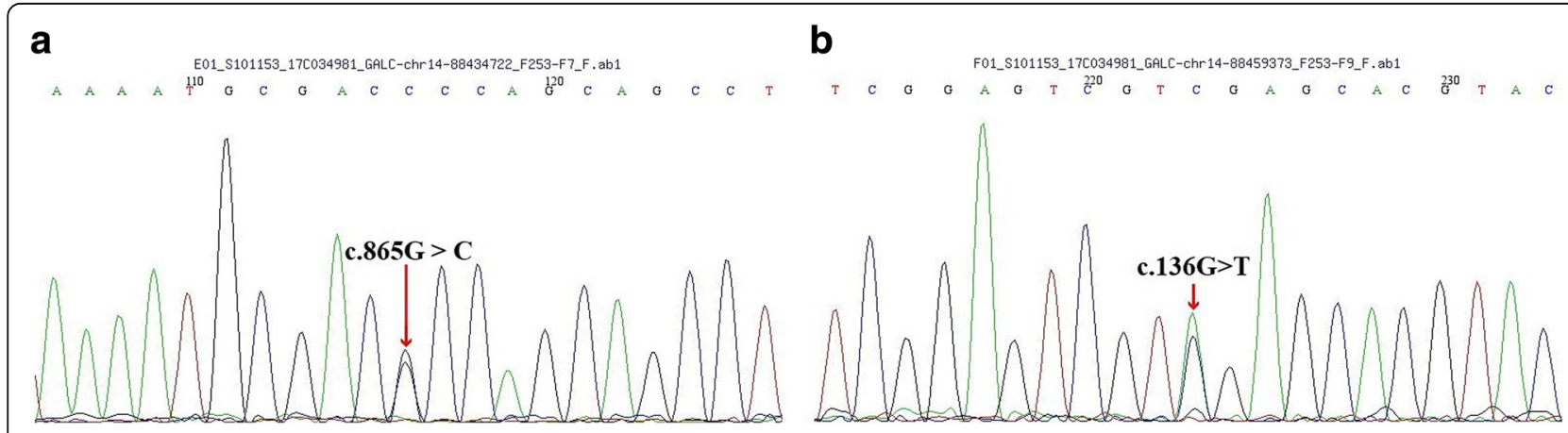

Fig. 1 Molecular genetic analysis of the GALC gene showed the two mutations, c.865G > C inherited from the patients' mother (a) and c.136G > $T$ inherited from their father (b) 


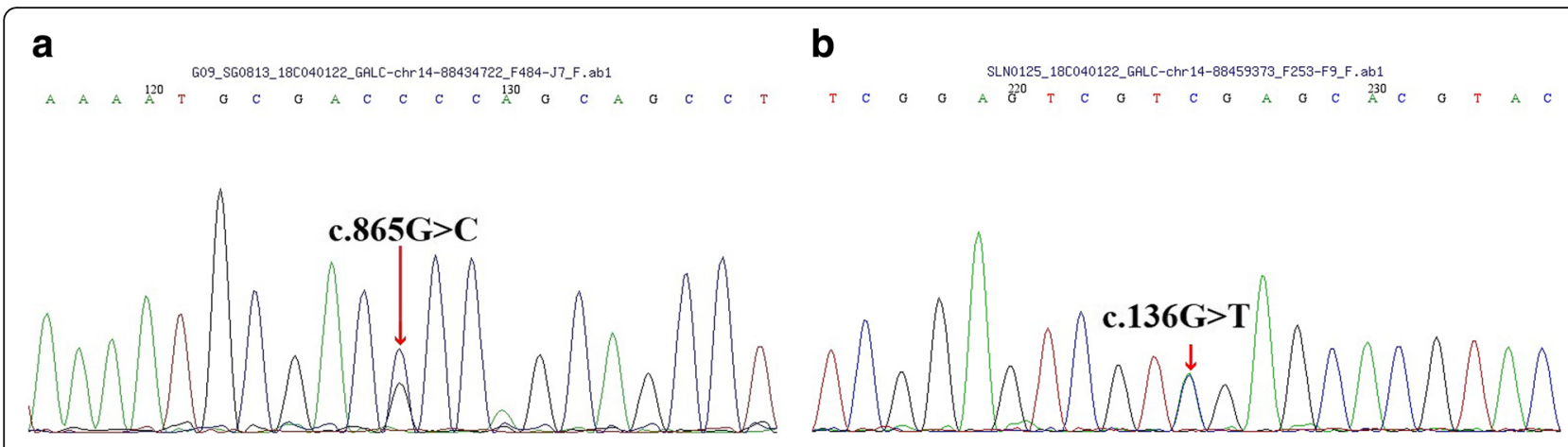

Fig. 2 The sister was heterozygous for the GALC mutation c.865G > C (a) and heterozygous for C.136G > T (b)

with neuro-nutrition drugs, such as $30 \mathrm{mg}$ per day vitamin B-1 and $1.5 \mathrm{mg}$ per day vitamin B-12 for about 1 month. But his condition was not relieved.

\section{Discussion and conclusions}

Several Chinese cases were reported, and more were scattered cases. A study investigated the clinical symptoms of 22 unrelated Chinese patients diagnosed with Krabbe disease. They found the late-onset form of Krabbe disease was more prevalent kind in patients [11].

We described two individuals from a Chinese family affected with spastic paraparesis. Herein, we made a comparison between the two patients' clinical presentation and with other published Chinese cases [10-21] (Table 2). Motor regression, spasticity, hearing and vision impairment, irritability and excessive crying presented in the early-infantile patients. Mental and motor regression, vision impairment were the main symptoms of the late-infantile patients. The juvenile patients had walking impairment and mental regression as main symptoms. The adult patients were heterogeneous with various symptoms included spastic gait disturbance, hemiplegia, vision impairment, aphasia and mental regression. Comparison to the Patients 1, the Patient 2 had severer symptoms. By the age of 22, she had become wheelchair-bound and demented.
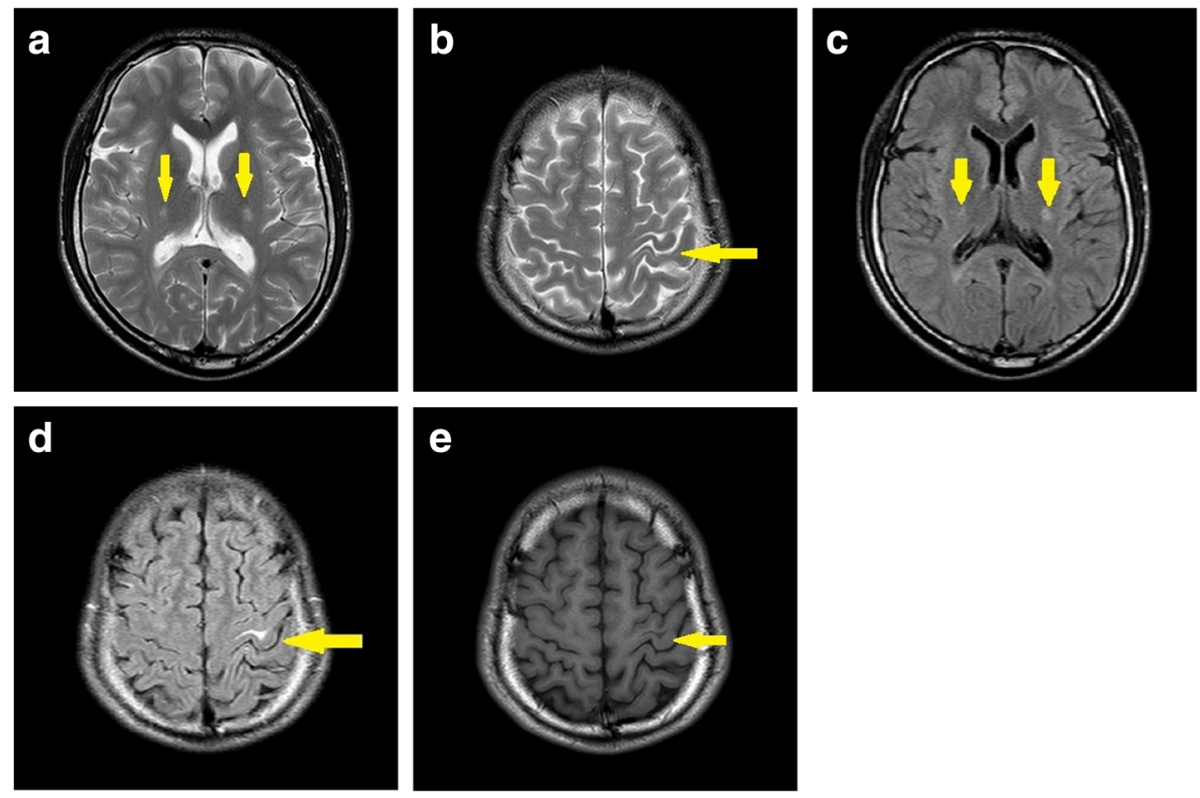

Fig. 3 Cerebral MR scans of the patient 1. The axial T2w and FLAIR image showed bilateral corticospinal tracts (a and $\mathbf{c}$ ) and the left central gyrus cortex (b and $\mathbf{d}$ ) signal hyperintensities. Cerebral T1w axial images (e) revealed a decreased signal in the left central gyrus cortex 

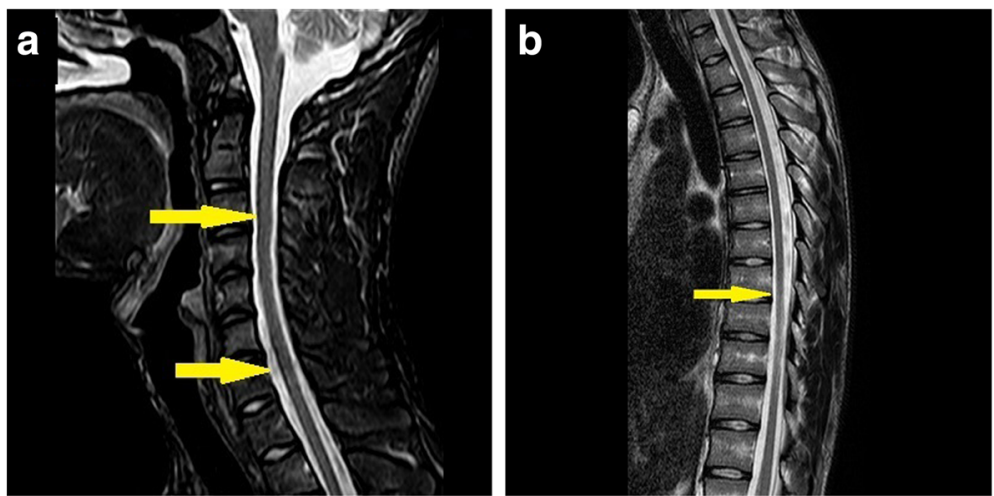

Fig. 4 Spinal T2w axial images (a and $\mathbf{b}$ ) showed mild atrophy of spinal cord

In the Patient 1, electromyography indicated peripheral nerve demyelination, while brain MRI showed an increased signal intensity in the white matter encompassing the bilateral corticospinal tracts. The GALC enzymatic activity in leukocytes was $3.9 \mathrm{nmol} / \mathrm{mg} / 17$ h. In the Patient 2, the GALC enzymatic activity revealed $4.4 \mathrm{nmol} / \mathrm{mg} / 17 \mathrm{~h}$. These low activities proposed the diagnosis of Krabbe disease in both patients.

Furthermore, GALC gene mutations were found in the patients. The first novel mutation was a single nucleotide substitution (c.865G $>$ C) in exon 8 of the GALC gene, resulting in glycine substitution to arginine at position 289 (p. G289R). This mutation was heterozygous in the proband's mother. The second mutation (c.136G $>\mathrm{T}$ ) found in our patient was also a single nucleotide substitution in exon 1, which caused a substitution of aspartic acid to tyrosine at position 46 (p. D46Y). The two patients inherited this mutation from their father, who was heterozygous for the mutation. Interestingly, this mutation was reported in another patient with adult-onset, although no vision loss was reported [10, 22].

The phenotype and genotype for the Krabbe disease show considerable variation worldwide, thus rendering difficulty in accurate diagnosis [23]. The differential diagnosis includes hereditary spastic paraplegia, Charcot-Marie-Tooth disease, and Kennedy disease. Brain MRI and GALC activity assay are essential for patients manifesting chronic progressive corticospinal tract impaired. However, the relationship between the deficiencies in the lysosomal enzyme activities and the degree of clinical severity appears obscure [21, 24]. Both the two mutations are reported in the gnomad dataset (http://gnomad.broadinstitute.org). As there is no prior case report of Krabbe patients carrying the mutation (c.865G > C: p.G289R), the allele frequency information for p.G289S from gnomad is 4.067e-6, which suggests the mutation might be probably damaging. Furthermore, based on SIFT and Polyphen2, we suggest that the two mutations (c.865G > C: p.G289R and c.136G > T: p.D46Y) were "likely pathogenic."

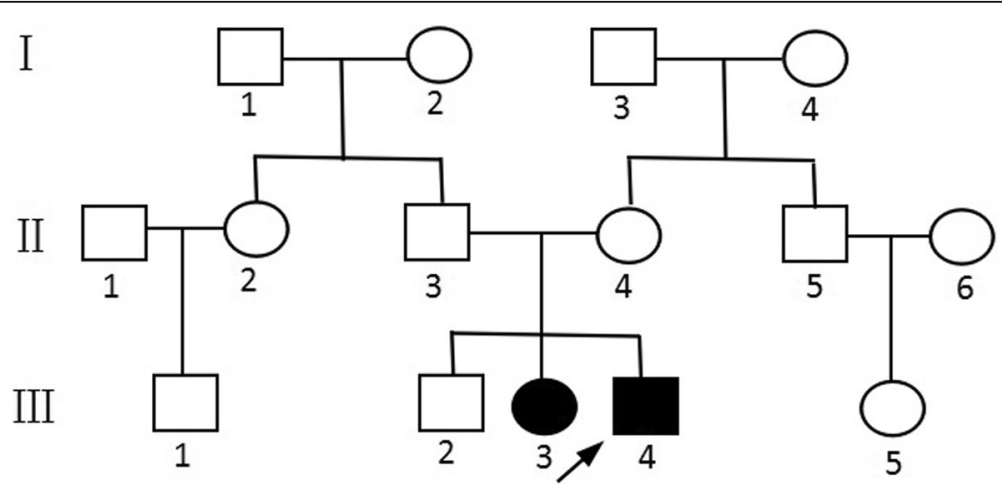

Fig. 5 Pedigree of the family 
Table 2 Clinical summaries of 41 Chinese Krabbe disease patients

\begin{tabular}{|c|c|c|c|c|}
\hline Patient No. & Sex & Age of Onset & Main symtoms & Reference \\
\hline 1 & $\mathrm{~F}$ & $2 \mathrm{~W}$ & cry less, eat less, move less, poor response to environment & [11] \\
\hline 2 & M & $2 \mathrm{M}$ & lose the ability to hold up his head, mental and motor regression & [16] \\
\hline 3 & M & $3 \mathrm{M}$ & lose the ability to hold up his head, hearing impairment, irritability and excessive crying & [20] \\
\hline 4 & $\mathrm{~F}$ & $4 \mathrm{M}$ & lose the ability to hold up her head, irritability and excessive crying & [12] \\
\hline 5 & M & $4 \mathrm{M}$ & lose the ability to hold up his head, irritability and excessive crying & [18] \\
\hline 6 & $\mathrm{~F}$ & $4 \mathrm{M}$ & Psychomotor regression,dyspepsia, feeding difficulties, irritability, hearing and vision impairment & [11] \\
\hline 7 & $\mathrm{~F}$ & $4 \mathrm{M}$ & irritability, feeding difficulties, vision impairment, convulsion opisthotonus & [11] \\
\hline 8 & M & $6 \mathrm{M}$ & Paroxysmal rigidity of the extremities, mental regression & [11] \\
\hline 9 & $\mathrm{~F}$ & $7 \mathrm{M}$ & psychomotor regression & [11] \\
\hline 10 & M & $8 \mathrm{M}$ & developmental delay, hypertonia of the extremities, vision impairment & [11] \\
\hline 11 & $\mathrm{~F}$ & $10 \mathrm{M}$ & motor regression, language development delay, hearing and vision impairment & [11] \\
\hline 12 & $\mathrm{~F}$ & $1 Y$ & motor regression, rigidity & [12] \\
\hline 13 & $\mathrm{~F}$ & $1 Y$ & language development delay, muscle weakness & [11] \\
\hline 14 & M & $1 Y 2 M$ & psychomotor regression, language development delay & [11] \\
\hline 15 & M & $15 \mathrm{M}$ & muscle weakness, walking impairment & [11] \\
\hline 16 & $\mathrm{~F}$ & $2 Y$ & mental and motor regression, vision impairment & [12] \\
\hline 17 & M & $2 Y$ & mental and motor regression, vision impairment & [15] \\
\hline 18 & M & $2 Y$ & psychomotor regression, rapid vision loss & [11] \\
\hline 19 & $\mathrm{~F}$ & $2 Y 5 \mathrm{M}$ & seizure, psychomotor regression & [11] \\
\hline 20 & M & $2 Y 8 M$ & mental and motor regression & [19] \\
\hline 21 & $\mathrm{~F}$ & $3 Y 2 M$ & psychomotor regression, vision impairment, dyspepsia, feeding difficulties & [11] \\
\hline 22 & M & $3 Y 5 \mathrm{M}$ & motor regression, seizure & [13] \\
\hline 23 & M & $3 Y 11 \mathrm{M}$ & walking impairment & [11] \\
\hline 24 & $\mathrm{~F}$ & $4 Y$ & mental regression, motor regression, spastic gait disturbance and dysarthria & Patient 2 \\
\hline 25 & M & $5 Y$ & spastic gait disturbance and vision impairment & Patient 1 \\
\hline 26 & M & $5 Y$ & weakness of both lower limbs & [15] \\
\hline 27 & M & $5 Y$ & muscle weakness, walking impairment & [11] \\
\hline 28 & M & $8 Y 10 M$ & walking and vision impairment & [11] \\
\hline 29 & M & $12 Y$ & spastic gait disturbance, weakness of both lower limbs & [21] \\
\hline 30 & M & $20 Y$ & weakness of left lower limb & [17] \\
\hline 31 & $\mathrm{~F}$ & $20 Y$ & psychomotor regression, aphasia & [11] \\
\hline 32 & $\mathrm{~F}$ & $29 Y$ & weakness of right lower limb & [20] \\
\hline 33 & $\mathrm{~F}$ & $30 Y$ & spastic gait disturbance,weakness of both lower limbs & [21] \\
\hline 34 & $\mathrm{~F}$ & $37 Y$ & weakness of the left upper limb, walking impairment & {$[10]$} \\
\hline 35 & $\mathrm{~F}$ & $38 Y$ & weakness of both lower limbs, rigidity & [14] \\
\hline 36 & M & $45 Y$ & numbness and weakness of both lower limbs, rigidity & [14] \\
\hline 37 & M & unknown & motor regression & [11] \\
\hline 38 & $\mathrm{~F}$ & unknown & psychomotor regression & [11] \\
\hline 39 & M & unknown & mental regression, walking impairment, hearing and vision impairment & [11] \\
\hline 40 & M & unknown & left limb movement disorder & [11] \\
\hline 41 & M & unknown & walking impairment & [11] \\
\hline
\end{tabular}


The present study describes two GALC mutations shared by two Chinese siblings with juvenile-onset of Krabbe disease and decreased GALC enzyme activity. These mutations might contribute towards increasing the public awareness about Krabbe disease and enriching the pathogenic database of GALC.

\section{Abbreviations}

BAEP: Brainstem auditory evoked potential; FLAIR: Fluid-attenuated inversion recovery; GALC: Galactocerebrosidase; HGMD: Human Gene Mutation Database; MRI: Magnetic resonance imaging; VEP: Visual evoked potentials

\section{Acknowledgements}

The authors wish to thank every departments of the First People's Hospital of Huizhou City.

\section{Authors' contributions}

SZ made contributions to acquisition of data, analysis and interpretation of data, and wrote the manuscript. LK and $C L$ conducted the manuscript editing, provided insightful thoughts and design. LC and TZ revised the manuscript critically for important intellectual content. All authors read and approved the final manuscript.

\section{Funding}

This study was supported by Natural Science Foundation of Guangdong Province, China (No. 2015A030313834, to CL). The funding body played a role in collection, analysis, and interpretation of data.

\section{Availability of data and materials}

The authors declare that all the data are contained within the manuscript.

\section{Ethics approval and consent to participate}

The Ethics Committee of the First People's Hospital of Huizhou city approved the study protocol. An informed written consent was taken from the patients to participate in the study.

\section{Consent for publication}

A written informed consent in a local language, approved by the Ethics Committee of the First People's Hospital of Huizhou city, was provided by the Patient 1 and their mother, on the Patient 2's behalf. The consent covered the publication of potentially identifying personal and medical information including any associated images. A copy of the consent is available for review by the Editor of this journal.

\section{Competing interests}

The authors declare that they have no competing interests.

Received: 26 March 2019 Accepted: 24 May 2019

Published online: 11 June 2019

\section{References}

1. Debs R, et al. Krabbe disease in adults: phenotypic and genotypic update from a series of 11 cases and a review. J Inherit Metab Dis. 2013;36(5):859-68

2. Hossain MA, et al. Late-onset Krabbe disease is predominant in Japan and its mutant precursor protein undergoes more effective processing than the infantile-onset form. Gene. 2014:534(2):144-54.

3. Xu C, et al. Six novel mutations detected in the GALC gene in 17 Japanese patients with Krabbe disease, and new genotype-phenotype correlation. J Hum Genet. 2006;51(6):548-54

4. Tappino B, et al. Identification and characterization of 15 novel GALC gene mutations causing Krabbe disease. Hum Mutat. 2010;31(12):E1894-914.

5. Kardas F, et al. A novel homozygous GALC mutation: very early onset and rapidly progressive Krabbe disease. Gene. 2013;517(1):125-7.

6. Krägeloh-Mann I, et al. Late onset Krabbe disease due to the new GALC p Ala543Pro mutation, with intriguingly high residual GALC activity in vitro. Eur J Paediatr Neurol. 2017;21(3):522-9.

7. Matthes F, et al. Enzyme replacement therapy of a novel humanized mouse model of globoid cell leukodystrophy. Exp Neurol. 2015;271:36-45.
8. Zerkaoui M, et al. Clinical and molecular report of novel GALC mutations in Moroccan patient with Krabbe disease: case report. BMC Pediatr. 2015;15: 182.

9. Zheng JP, Sheng HY, L HY. The clinical features and molecular genetic assay of globoid cell leukodystrophy (Krabbe disease). Chin J Pediatr. 2014;29(5); 367-72.

10. Da YW, et al. Clinical and imaging features and genetic analysis of a case with adult-onset Krabbe disease. Zhonghua Yi Xue Yi Chuan Xue Za Zhi. 2013:30(5):585-8

11. Zhao $\mathrm{S}$, et al. Large-scale study of clinical and biochemical characteristics of Chinese patients diagnosed with Krabbe disease. Clin Genet. 2018:93(2): 248-54.

12. Chen XC, Al E. Detection of galactocerebrosidase activity in dried blood spots. Int J Pediatr. 2015;4(471-473)

13. Ma XW, Zhao JY, Zhu LN. Application of next generation sequencing technology for genetic diagnosis of a case with globoid cell leukodystrophy. J Clin Pediatr. 2017:(8):35:625-8.

14. Mao CH, Xie MQ, Liu CY. Adult onset leukodystrophy manifested as spastic paraplegia. Chin J Neurol. 2015:(9):48,748-52

15. Zhang HW, F GX, YE J. Sphingolipidoses of lysosomal storage disorders. J Clin Pediatr. 2010;28(3):201-6.

16. Zhang Y, Ding Y, LI XY. The clinical and genetic features of early-onset globoid cell leukodystrophy in one boy. J Clin Pediatr. 2014;(10):976-9.

17. Zhang T, et al. Adult-onset Krabbe disease in two generations of a Chinese family. Annals of translational medicine. 2018;6(10):174-174-174.

18. Ren XT, Yang Y, Wang CZ. A case of Krabbe disease. Zhonghua Er Ke Za Zhi. 2013;51(1):69-70.

19. Wang $X$, et al. The use of targeted genomic capture and massively parallel sequencing in diagnosis of Chinese leukoencephalopathies. Sci Rep. 2016;6: 35936.

20. Yang $Y$, et al. Four novel GALC gene mutations in two Chinese patients with Krabbe disease. Gene. 2013;519(2):381-4.

21. Lim SM, et al. Patient fibroblasts-derived induced neurons demonstrate autonomous neuronal defects in adult-onset Krabbe disease. Oncotarget. 2016:7(46):74496-509.

22. Shao Y, et al. Mutations in GALC cause late-onset Krabbe disease with predominant cerebellar ataxia. neurogenetics. 2016:17(2):137-41.

23. Liao P, Gelinas J, Sirrs S. Phenotypic variability of Krabbe disease across the lifespan. Can J Neurol Sci. 2014:41(1):5-12.

24. Xu C, et al. Six novel mutations detected in the GALC gene in 17 Japanese patients with Krabbe disease, and new genotype-phenotype correlation. J Hum Genet. 2006:51(6):548-54

\section{Publisher's Note}

Springer Nature remains neutral with regard to jurisdictional claims in published maps and institutional affiliations.
Ready to submit your research? Choose BMC and benefit from:

- fast, convenient online submission

- thorough peer review by experienced researchers in your field

- rapid publication on acceptance

- support for research data, including large and complex data types

- gold Open Access which fosters wider collaboration and increased citations

- maximum visibility for your research: over $100 \mathrm{M}$ website views per year

At BMC, research is always in progress.

Learn more biomedcentral.com/submissions 